\title{
A Real-Time Data Set for Switzerland ${ }^{a}$
}

\author{
Ronald INDERGAND ${ }^{\mathrm{b}}$ and STEFAN LeisT ${ }^{\mathrm{c}}$
}

JEL-Classification: C82, E30

Keywords: real-time data, data revisions

\section{Introduction}

How informative are initial estimates of macroeconomic data? How good is a specific forecasting model? Are empirical findings robust to data revisions? A real-time data set is needed to address these questions. The literature examining the relevance of data-revisions for applied economic research acknowledges this necessity and has a long tradition. Moreover, it is expanding rapidly after comprehensive data sets have become available for many countries (see below). In what follows, we provide a short overview of typical applications of such data. See Croushore (2011) for an extensive review of the literature. ${ }^{1}$

Initiated by the seminal work of Diebold and Rudebusch (1991), a canonical view concerning forecasting excercises has emerged which asserts that, in the presence of data revisions, any evaluation of economic predictions should rely on realtime data sets (see, e.g., Croushore, 2011). Otherwise, forecasters might rely on a model which provides reasonable forecasts in a pseudo-out-of-sample ${ }^{2}$ exercise

a This project was supported by the State Secretariat of Economic Affairs, Switzerland (SECO). The views and opinions expressed in this paper are solely those of the authors and are not necessarily those of the SECO. Particular thanks go to Bernhard Weber (SECO) who kindly provided us with historical vintages of Swiss employment. We are also very grateful to Isabel Martinez, Klaus Neusser, Bruno Parnisari, Christoph Sax and Peter Steiner who supported us during several stages of the project.

b Swiss State Secretariat for Economic Affairs, University of Bern. Email: ronald.indergand@ gmx.ch.

c Swiss State Secretariat for Economic Affairs. Email: stefan.leist@gmx.ch.

1 Dean Croushores bibliography on real-time data literature also contains a large collection of papers: https://facultystaff.richmond.edu/ dcrousho/.

2 In a pseudo-out-of-sample forecasting exercise data ranging from $t=1, \ldots, T$ is available. To perform forecasts you then estimate a model using only $t=1, \ldots, T-k$ observations, where $k$ is an arbitrary chosen integer. The forecasts from this model generate data for $t=T-k+1, \ldots, T$ which is compared to the actual value. This approach provides information on the preciseness of forecasts only if the data is not subject to revisions. 
but potentially contains indicators that are heavily revised and, therefore, probably not useful in a forecasting context. As a result, it has become standard in the literature to work with real-time data for assessing the quality of forecasting models.

Similarly, if the aim is to evaluate policy decisions of the past, ignorance of revisions may lead to erroneous conclusions (see, e.g., Orphanides, 2001; Croushore and Evans, 2006). Moreover, Orphanides and Van Norden (2005) show that real-time issues are important for the assessment of inflationary pressures. Furthermore, the results of empirical economic research in general may depend on the data vintage at hand (Anderson, 2006). Indeed, Croushore and Stark (2003) show that some key macroeconomic results presented in the literature may not be robust to the selection of different data vintages.

Another strand of literature examines the efficiency of first data releases by the statistical agencies. A predictable revision process would imply potential for improvement of first releases. Faust, Rogers, and Wright (2005), Aruoba (2008) and Corradi, Fernandez, and Swanson (2009) address this question and find predictable revisions to GDP and other variables for several G7 countries. Other authors model the data revision process in order to extract information about the true values and improve on the preliminary data (see, e.g., JACOBS and Van Norden, 2011; Cunningham et al., 2012).

Applied research employing real-time data for Switzerland is rather scarce to date. Some notable exceptions include AMSTAD and Fischer (2009) who are the first to show that weekly updates of inflation-nowcasts are informative. JORDAN et al. (2005) and Cuche-Curti, Hall, and Zanetti (2008) show that revisions to Swiss GDP are an important source of uncertainty for monetary authorities and may lead to suboptimal monetary policy decisions. Kholodilin and SiliVERSTOvs (2012) employ a partly real-time data set to show that business tendency surveys (BTS) can be useful for predicting GDP using a dynamic factor model. Other authors find that BTS are able to predict revisions in the case of GDP during a short subperiod of their total sample (SiLIVERstovs, 2012), as well as in the case of current account data for certain types of revisions (JACOBS and Sturm, 2008). Finally, Siliverstovs (2013) shows that the chronology of the Swiss business cycle is robust across real-time data vintages.

The above mentioned research has been spurred by the release of real-time databases. The most notable examples of such databases include Croushore and Stark (2001) for the U.S. ${ }^{3}$, Giannone et al. (2012) for the Euro-Area ${ }^{4}$,

3 http://www.phil.frb.org/research-and-data/real-time-center/real-time-data/.

4 http://www.eabcn.org/eabcn-real-time-database. 
Egginton, Pick, and Vahey (2002) and Castle and Ellis (2002) for the UK and Knetsch (2009) for Germany ${ }^{6}$. Furthermore, there exists a real-time database provided by the $\mathrm{OECD}^{7}$ including many variables for most of its member states. Fernandez et al (2012) extend this data set by short windows of historical vintages (consisting of about 10 quarters for each vintage). ${ }^{8}$

So far, to the best of our knowledge, Swiss researchers have not been given access to a public and comprehensive real-time data set. 'The OECD real-time database includes data for Swiss variables. However, the data is heavily rounded in case of several vintages and variables (e.g., GDP), yielding zero-growth rates for many quarters. Additionally, the usage of the data proves to be somewhat cumbersome as the edition dates (vintage dates) do not always correspond to the official release dates of the QNA figures. We fill this gap for Switzerland by providing real-time data on national accounts, labor market statistics, prices and interest rates. For comparison and because measures for foreign economic activity are vital in models of a small open economy, we also include real-time data of U.S., Euro Area 17 (E.A. 17) and Japanese GDP. The construction of the data set is described in Section 2. Section 3 provides a brief analysis of revisions to Swiss GDP and compares it to other countries. We find that revisions in Switzerland are similar in scope as in other countries. However, country-specific particularities of the revision processes may influence a statistical analysis and should be taken into account in international comparisons.

\section{The Data Set}

\subsection{Definitions}

Real-time data for a given variable is stored in matrix form, as Table 1 shows. The row labels represent the usual time axis, $t$, of a time series whereas the column labels consist of the different release dates, $v$, of the series. Such a column is commonly referred to as a vintage and contains the most up-to-date information

5 http://www.econ.cam.ac.uk/research/keepitreal/keepitreal/index.htm and http://www. bankofengland.co.uk/statistics/Pages/gdpdatabase/default.aspx.

6 http://www.bundesbank.de/Navigation/EN/Statistics/Time_series_databases/Real_Time_ Data/realtime_zeitreihen_node.html

7 http://stats.oecd.org/mei/default.asp?rev=1

8 http://www.rthd-oecd.org

9 Bernhard (forthcoming) will provide vintages for Swiss GDP. 


\section{Table 1: Vintages of Swiss GDP}

\begin{tabular}{|c|c|c|c|c|c|c|c|c|}
\hline & & 2006 Q1 & 2006 Q2 & 2006 Q3 & $2006 Q 4$ & 2007 Q1 & 2007 Q2 & 2007 Q3 \\
\hline 2004 & Q1 & 107035786100 & 106958170500 & 107130657300 & 107123282400 & 107108887400 & 107100207600 & 109299794900 \\
\hline 2004 & 02 & 107084259100 & 107065443100 & 107454478300 & 107448934800 & 107452424500 & 107446665600 & 109726416900 \\
\hline 2004 & Q3 & 107220869400 & 107229818500 & 107614244100 & 107628360700 & 107627164900 & 107631258200 & 109625977000 \\
\hline 2004 & Q4 & 107301969300 & 107407358100 & 107816675100 & 107818905900 & 107833411200 & 107855056800 & 110195541200 \\
\hline 2005 & 01 & 107815565000 & 107724200300 & 108170675400 & 108159942800 & 108141632100 & 108117321900 & 110911475100 \\
\hline 2005 & Q2 & 108773313000 & 108738147600 & 109109336600 & 109095140300 & 109100042700 & 109088799000 & 111893952100 \\
\hline 2005 & Q3 & 109700609400 & 109701542700 & 110105684900 & 110132200400 & 110127193700 & 110134642800 & 112783236500 \\
\hline 2005 & Q4 & 110277485500 & 110424785000 & 110876039000 & 110878107000 & 110893293200 & 110934991700 & 113838314600 \\
\hline 2006 & Q1 & NA & 111457016200 & 111709154200 & 111648104600 & 111637322000 & 111594859300 & 114804479600 \\
\hline 2006 & Q2 & NA & NA & 112527759600 & 112327045500 & 112386743400 & 112367559800 & 115530816900 \\
\hline 2006 & 03 & NA & NA & NA & 112739072000 & 112852772700 & 112862703500 & 116501235800 \\
\hline 2006 & Q4 & NA & NA & NA & NA & 113364145400 & 113429946600 & 117127892200 \\
\hline 2007 & Q1 & NA & NA & NA & NA & NA & 114316995400 & 117896170800 \\
\hline 2007 & Q2 & NA & NA & NA & NA & NA & NA & 118769102400 \\
\hline 2007 & Q3 & NA & NA & NA & NA & NA & NA & NA \\
\hline 2007 & Q4 & NA & NA & NA & NA & NA & NA & \\
\hline
\end{tabular}

Notes: This is a screenshot of the printed vintages in the R console (RStudio). The data in the excelfiles are also downloadable and are organized in the same manner.

available at that time for the series. In what follows, we denote the time index $t$ as a subscript and the vintage time index $v$ as a superscript, e.g., $x_{t}^{v}$. The natural $\log$ of a variable $X$ is denoted by $x$.

Our data set consists of vintages as they were available at a particular release date of the quarterly national accounts (QNA). We chose the QNA release date, rather than another point in time, for the following reason. Shortly after the QNA data are published, various professional forecasters update their economic predictions using the most recent information available. Thus, for any forecast evaluation excercise - possibly involving the professionals' forecasts as benchmarks - it is important to have their state of information readily available. The QNA estimates for Switzerland are computed by the State Secretariat for Economic Affairs (SECO) about 60 days after the end of a quarter. For example, $G D P_{1980 q 1-2014 q 1}^{2014 q 2}$ was published on May 28, 2014 (i.e., the release quarter is $v=2014 q 2$ ) and contains quarterly data on GDP starting from the first quarter 1980 to the first quarter $2014 .^{10}$

10 The release dates varied somewhat but usually were in March, at the end of May / beginning of June, in September and at the end of November / beginning of December. We relied on a quarterly notation in the superscript to enhance readability. The exact publication dates are included in the database whenever possible. 


\subsection{The Variables}

Table 2 provides an overview of the variables covered by the database so far. The data set is balanced in order to facilitate the usage of the data, i.e., the vintages were retropolated or completed when necessary. We performed seasonal adjustment if seasonal patterns have not already been removed beforehand. Any of these adjustments and transformations are outlined below and are flagged in the data set. Hence, if desired, the user can choose to work with the unbalanced data. The seasonally unadjusted vintages are also provided for the variables that were seasonally adjusted by the autors.

The first vintage is denoted by $v=2002 q 4$ and contains data ranging from $1980 q 1$ to $2002 q 3$. All subsequent vintages also start in $1980 q 1$ and each vintage contains an observation more than the vintage before as well as all revised data. The final vintage is $v=2014 q 2$ containing data from $1980 q 1$ to $2014 q 1$. The data set can be downloaded from this journal's homepage (http://www.sjes. ch/published.php?Year=2014), including some metadata. All subsequent updates, changes or extensions of the data set will be documented and provided on http:// www.seco.admin.ch/themen/00374/00456/.

Table 2: Variables Contained in the Data Set

\begin{tabular}{ll}
\hline National Accounts Data & GDP (real, sa) \\
& Government Consumption (real, sa) \\
& Private Consumption (real, sa) \\
& Gross Investment (real, sa) \\
& Total Exports (real, sa) \\
& Total Imports (real, sa) \\
& GDP Deflator (sa) \\
& Consumer Price Index (nsa, sa) \\
& Nominal Interest Rate \\
& Real Interest Rate (ex-post) \\
\hline Prices \& Financials & Employment (nsa, sa) \\
& Registered Unemployed (nsa, sa) \\
& Unemployment Rate (nsa, sa) \\
\hline Labor Market Data & Foreign GDP Proxy (real index, sa) \\
& GDP, USA (real, sa) \\
\hline Foreign Data & GDP, E.A. 17 (real, sa) \\
& GDP, Japan (real, sa) \\
\hline
\end{tabular}




\section{National Accounts}

For GDP, government and private consumption, investment, exports, imports and the GDP deflator, the main sources were the archives of the SECO and the OECD real-time database, provided the data in the latter was not rounded too heavily. All variables were available seasonally adjusted and, apart from the GDP deflator, in volume terms (usually chain-linked ${ }^{11}$ ). For some variables, $j$, the start of the time index $t$ varied across vintages. In these cases, we used growth rates of the previous vintage to retropolate the data in order to achieve a balanced data set, starting in $1980 q 1 \forall v, j$. Table 4 provides the details.

\section{Labor Market}

Vintages for total employment (full time equivalents) are available for $v=2002 q 4-2014 q 2 .{ }^{12}$ For $v \in\{2011 q 2,2011 q 3\}$, the Swiss Federal Statistical Office (SFSO) released employment with a delay - that is, after the QNA estimate took place. In these cases, the SECO relied on internal estimates which we included in order to achieve a balanced data set. All vintages of total employment were seasonally adjusted using the automated procedure of X-13ARIMASEATS without outliers. ${ }^{13}$

The unemployment rate was constructed with the registered unemployed in the nominator and the labour force in the denominator. In principle, we followed the official calculation, where the denominator, i.e., the working population (WP) from the Census, remains fixed for about a decade. It gets updated approximately three years after the new Census has been conducted and then remains fixed for about another decade. ${ }^{14}$ However, this procedure is agnostic of any quarterly changes in the total number of employees and hence, in case of a growing workforce, somewhat overestimating the unemployment rate as time passes. In order to dampen this effect, we linearly interpolated the growth of the workforce between two Censuses and only held the most recent figure from the Census constant as

11 The transition from volumes measured at constant prices to the chain-linking method occured by the end of 2003 for the yearly series. The QNA got adjusted to these yearly aggregates in $2004 q 1$ but experienced further revisions in the course of 2004 and 2005 (see Section 3.1).

12 For $v=2002 q 4-2012 q 3$ they were provided by Bernhard Weber (SECO).

13 Although this is a rather ad-hoc approach, we believe that it delivers useful seasonally adjusted data. Appendix 8 offers some details on the models chosen for seasonal adjustment. However, the real-time data is also provided not seasonally adjusted. Hence, researchers are enabled to perform there own seasonal adjustement.

14 See, e.g., SECO (2014). Starting in 2010, annual register data supplemented by surveys serves as a new Census and replaces the former decennial Census. Therefore, the base may be changed more frequently in the future. 
formally described in Appendix 6. Since this adjustment of the denominator is rather ad-hoc, we also included vintages of the registered unemployed (no revisions) in the data set. Seasonal adjustment of the resulting unemployment rate and of the registered unemployed was conducted using the automated procedure of X-13ARIMA-SEATS without outliers. Appendix 8 offers some details.

\section{Prices and Interest Rates}

Vintages for the consumer price index (CPI) were taken from the OECD realtime database and from the SFSO-homepage.. The same procedure for seasonal adjustment as above was applied to all vintages of the CPI. An ex-post real interest rate was computed by substracting year-on-year CPI-inflation (nsa) from the nominal interest rate, which is not subject to revisions.

$$
R R_{t}^{v}=I_{t}-100 \cdot\left(c p i_{t}^{v}-c p i_{t-4}^{v}\right)
$$

The 3-month London Interbank Offered Rate (LIBOR) ${ }^{15}$ is used as a nominal interest rate, $I_{t}$, expressed in percentage points. The British Bankers' Association started the official calculation in $1989 \mathrm{~m} 1$. In order to achieve a balanced data set, we retropolated the LIBOR series using monthly growth rates of the 3-month Swiss Franc Euromarket interest rate. ${ }^{16}$ The correlation between the two rates during the overlapping period $(1989 \mathrm{~m} 1$ to $2007 \mathrm{~m} 10)$ is 0.998 .

\section{Foreign GDP}

Vintages of real, seasonally adjusted GDP for the U.S., Japan and the E.A. 17 were taken from the OECD real-time database. In case of the E.A. 17, the OECD database does not provide any information for $G D P_{2008 q 1}^{2008 q 2}$ and $G D P_{2008 q 1-2008 q 2}^{200893}$. However, quarterly estimates for the E.A. 15 were publicly available and growth rates can be accessed in Eurostat (2008a, b). We used this data to extrapolate the missing GDP figures for the E.A. 17.

In order to obtain a proxy for foreign economic activity $\left(G D P^{f}\right)$, we weight the growth rates of real, seasonally adjusted GDP of the three regions by their share of the sum of nominal GDP (NGDP) measured in Euros. ${ }^{17}$ Because the nominal levels of the most recent vintage for the euro area were often published with

15 Downloadable from http://www.snb.ch/de/iabout/stat/statpub/statmon/stats/statmon/ statmon_E1.

16 Downloadable from http://www.snb.ch/de/iabout/stat/statpub/histz/id/statpub_histz_actual

17 An alternative to consider would be a trade-weighted proxy, requiring real-time vintages of exports by countries, however. 
a delay, we use the vintage published one quarter earlier $(v-1)$, see Appendix 7 for a detailed exposition. To convert U.S. and Japanese NGDP to Euros we use the spot exchange rates.

Using these growth rates for foreign economic activity, we construct an index for a proxy of the foreign GDP levels starting with $1980 q 1=100$.

In the remainder of this paper, we provide a short revision analysis for Swiss GDP. It serves as an example for a possible application of the database and illustrates that revisions to national accounts data in Switzerland may be large and similar to those in other countries.

\section{An Example: Revisions to Swiss GDP}

\subsection{Why Revisions?}

There are several causes for revisions to a published data series. In case of the Swiss QNA data, we classify the reasons for revisions into five groups. ${ }^{18}$

\section{Revisions to Quarterly Indicators}

The QNA estimates in Switzerland are based on the inter- and extrapolation techniques described and implemented in R by $S_{A X}$ and STEIner (2013). Thus, every revision to an indicator used for temporal disaggregation affects the final quarterly series. Revisions to the quarterly indicators may occur at any time and usually affect the most recent quarters of an indicator.

\section{Revisions to Annual Base Data}

The aggregates of the annual national accounts (ANA) are computed by the SFSO and get released every year in August. At the same time the two previous years get revised. For example, in August 2013, the SFSO released annual figures for 2012. In addition, the ANA data for 2011 got revised for the first time and the figures for 2010 for the second time. Yearly data before that is regarded as definitive and remains unrevised apart from benchmark revisions. Whenever the SFSO releases new ANA data, the QNA data computed by the SECO are to be adjusted to those yearly reference values.

18 The Swiss QNA benchmark revisions correspond to the definition of major revisions in EuroSTAT (2013). The other four types of Swiss QNA revisions may all be classified as routine revisions. 


\section{Changes in Methodology (Benchmark Revisions)}

Concepts as well as the methodology for the computation of national accounts are subject to development. For example, Swiss national accounts may be adjusted to new international standards, or the method of computing quarterly GDP may fundamentally alter. Such changes are large and may affect the dynamics and levels of the whole time series. Usually, they are not introduced gradually but at a specific date and are often called benchmark revisions. The vintage time span covered by our data set, for example, in case of Swiss quarterly GDP includes five benchmark revisions. In $v=2004 q 1$ all QNA variables were preliminarily adjusted to the new yearly aggregates which got revised according to the European System of Accounts (ESA) $1995^{19}$. In $v=2006 q 1$ the production approach was introduced as the principal method for quarterly GDP estimation. In $v=2007 q 3$ the estimation method of various annual GDP components changed which greatly affected aggregate GDP. The seasonal adjustment methodology was fundamentally altered in $v=2009 q 1$ with the transition from direct to indirect adjustment of GDP. The transition to NOGA ${ }^{20} 2008$ occured in $v=2012 q 3$. Furthermore, $v=2014 q 3$ will feature the adjustment to the ESA 2010 for all Swiss QNA components.

\section{Minor Changes in the QNA Estimation Methods}

In the QNA, the statistical methods and indicators employed for temporal disaggregation are under constant monitoring and may be subject to changes. For example, a discontinuation of any indicator demands a replacement, which may feature slightly different quarterly dynamics or somewhat different seasonal patterns. Hence, the model used for the temporal disaggregation or seasonal adjustment may be changed as well.

\section{Technical Reasons}

Even without revisions to the yearly aggregates or the quarterly indicators and without methodological changes of the QNA estimation, slight revisions occur due to the nature of the econometric techniques used for temporal disaggregation. For example, any new data point of a not seasonally adjusted series will lead

19 In the course of 2004 and 2005, the QNA was further revised in the context of the transition to ESA 1995. The transition also included the introduction of the chain-linking method for the calculation of real values.

20 Nomenclature Générale des Activitées Économiques - the Swiss counterpart to the Statistical Classification of Economic Activities in the European Community (NACE). 
to new regression coefficients in the model used for seasonal adjustment and, thus, the resulting seasonally adjusted figures will be slightly different for the whole time span of the series.

\subsection{Revisions to GDP}

Revisions to national accounts data can be large and might have great implications on policy making as well as applied economic work. Switzerland is no exception as Figure 1 shows. The graph depicts $\Delta g d p_{2003 q 2}^{v=2003 q 3-2014 q 2}$ on the vertical axis and the vintage time index on the horizontal axis. Hence, the dots represent releases of GDP growth rates for the quarter $t=2003 q 2$ and vintages $v=2003 q 3-2014 q 2$. This corresponds to one row of the triangular matrix in Table 1, however, we use growth rates instead of the levels presented in this table. As can be seen, releases of $\Delta g d p_{2003 q 2}$ vary within a range of almost 1 percentage point. Even changes in the sign occur several times. In particular, revisions can be strikingly high when a benchmark revision occurs (vertical lines). In contrast, all other revisions are rather small and usually peak when the QNA releases coincided with ANA releases.

Figure 2 shows further that this particular quarter is no exception (this time, the horizontal represents the usual time axis). Whereas the black line represents $\Delta g d p_{1980 q 1-2014 q 1}^{2014 q 2}$, the grey shaded area depicts the range of all published growth rates, $\Delta g d p_{t}^{v} \forall t, v$. Consistent with the conclusions in Siliverstovs (2013), it appears that the course of the business cycle gets not altered fundamentally by the revisions, although the growth rate for a particular quarter may be subject to substantial revisions. Nevertheless, it becomes also clear that revisions can by no means be neglected in Switzerland. For example, both the timing and scope of recessions and expansions may change, resulting in pictures such as Figure 1 where a quarterly estimate may indicate a contraction in an early release, and an expansion in a later release, or vice versa. However, revisions should not be interpreted as errors as long as they are not systematically biased. Instead, they indicate the incorporation of newly available or revised and therefore more precise source data, or the adoption of updated concepts or methods. 
Figure 1: Revision History, 2003q2 (44 Releases)

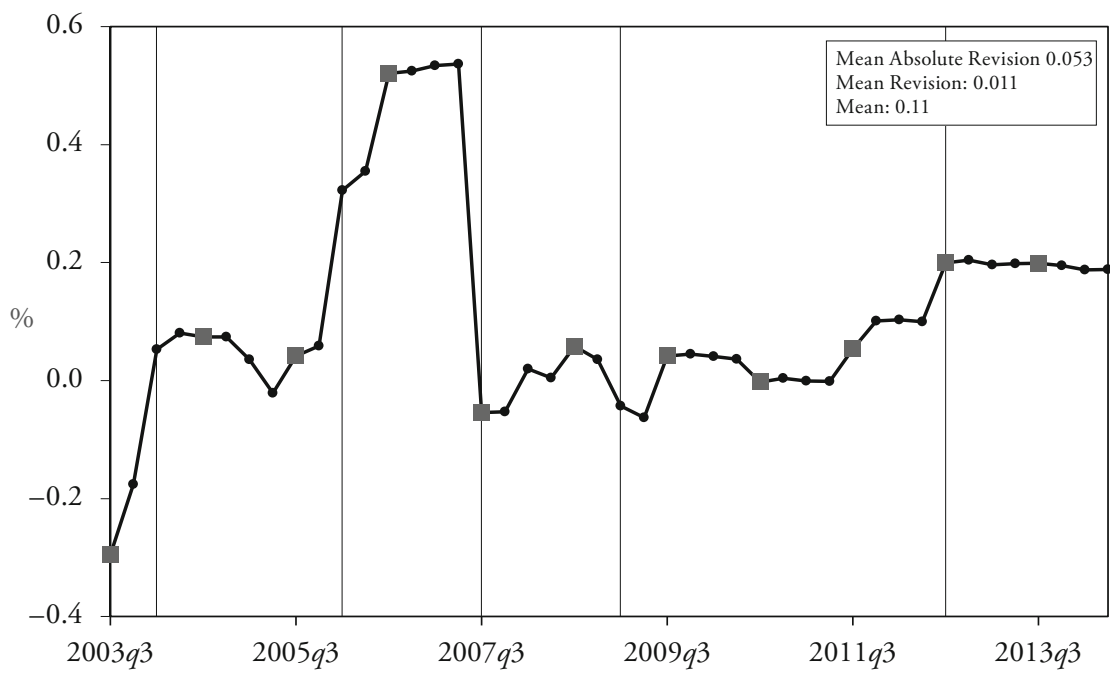

Notes: GDP growth rate of the second quarter 2003 as released in different vintages. Vertical lines correspond to first releases after major methodological revisions. Dots correspond to regular QNA releases. Squares correspond to QNA releases which coincided with ANA releases.

Figure 2: Revision History, Swiss GDP

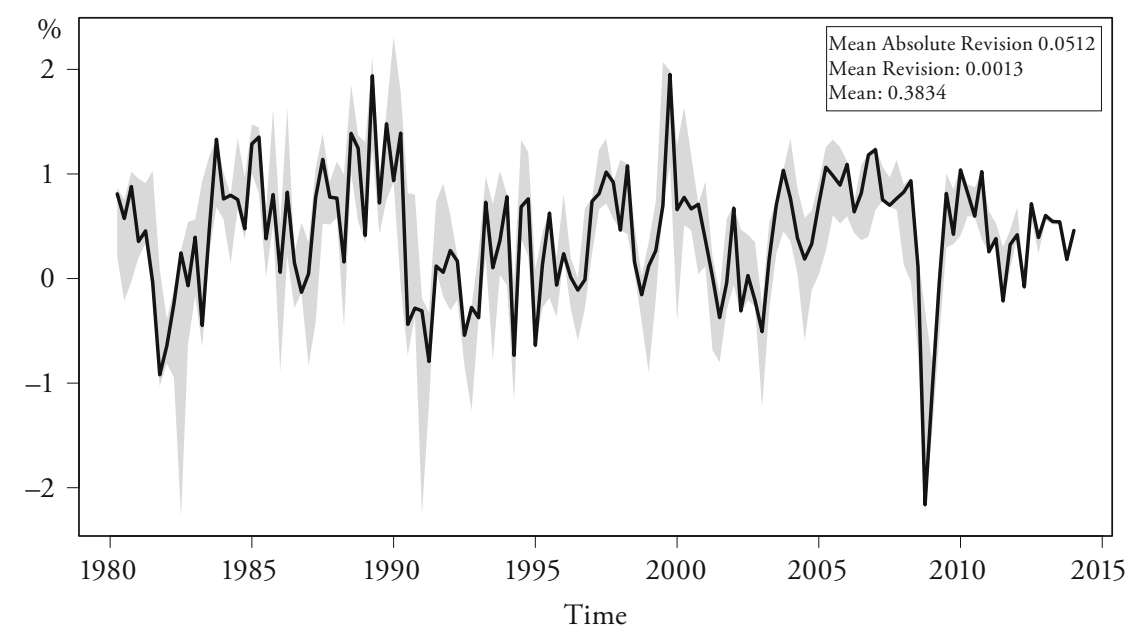

Notes: Black line is GDP growth as released in the vintage 2014q2. The grey shaded area covers the range of all growth rates released for a particular time across all vintages. Since for the latest quarter (2014q1) there exists just one vintage (2014q2), the shaded area reduces to a point. 


\subsection{Comparison with Other Countries}

Table 3 shows a comparison of some statistics related to revisions to quarterly GDP in Switzerland, the United States, the Euro Area and Japan. We look at two definitions of revisions. First versus last revisions are given by

$$
\begin{aligned}
r e v_{t}^{f v s} l & =\Delta g d p_{t}^{V}-\Delta g d p_{T}^{v}, \\
V & =2014 q 2, \\
v & =2002 q 4, \ldots, 2014 q 1, \\
t & =2002 q 3, \ldots, 2013 q 4
\end{aligned}
$$

where $V$ stands for the last vintage available in our data set, $T$ stands for the last observation in the usual time dimension of any given vintage $v$ and $\Delta$ takes differences over $t, \Delta x_{t}^{v}=x_{t}^{v}-x_{t-1}^{v}$. Therefore, the vector $\Delta g d p_{T}^{2002 q 4-2014 q 1}$ contains all initial (first) releases of a quarterly growth rate and the vector $\Delta g d p_{2002 q 3-2013 q 4}^{2014 q 2}$ contains the most recent estimate of all these quarterly growth rates. This corresponds to comparing the diagonal in Table 1 with the last column (in growth rates). First versus second revisions are defined as

$$
r e v_{t}^{f v s}=\Delta g d p_{T-1}^{v+1}-\Delta g d p_{T}^{v} .
$$

Hence, the vector of second releases, $\Delta g d p_{T-1}^{2002 q 4-2014 q 2}$, is compared with the vector of first releases, $\Delta g d p_{T}^{2002 q 4-2014 q 2}$.

We only consider quarters where initial releases are available in our data set or, put differently, we only use the triangular part of the GDP matrices, $t=2002 q 3-2014 q 1$. As a note of caution, Figure 1 suggests that large revisions usually occur during benchmark revisions. The number and timing of such revisions may differ across countries and, hence, statistics on data revisions should be compared carefully.

First versus last revisions are lowest in the E.A. 17. For the U.S., Japan and Switzerland the extent of the revisions looks similar. In the case of first versus second revisions, this picture does not change fundamentally. However, the first row of Table 3 shows that GDP growth rates have been different in the four countries and, therefore, revisions should be compared cautiously. These results are broadly speaking in line with FAUst, Rogers, and WRight (2005) who also find mean absolute revisions to be higher in Japan than in the U.S. but look at an earlier time span. Giannone et al. (2012) focus on a more similar period and 
Table 3: Comparison of Revisions to GDP-Growth Across Countries

\begin{tabular}{lcccc}
\hline & CH & USA & E.A. 17 & JP \\
\hline Mean growth of last vintage & 0.4580 & 0.4632 & 0.2054 & 0.2289 \\
Standard dev. of last vintage & 0.6123 & 0.6666 & 0.6847 & 1.1961 \\
\hline First vs. Last & & & & \\
Mean revision & 0.0914 & -0.1086 & 0.0199 & -0.0839 \\
& $(0.0663)$ & $(0.0497)$ & $(0.0280)$ & $(0.0785)$ \\
Mean abs. revision & 0.3183 & 0.2806 & 0.1478 & 0.3949 \\
Max. abs. revision & 1.8420 & 0.8959 & 0.4099 & 1.1820 \\
\hline First vs. Second & & & & \\
Mean revision & 0.0245 & -0.0086 & 0.0012 & -0.0232 \\
& $(0.0292)$ & $(0.0163)$ & $(0.0115)$ & $(0.0463)$ \\
Mean abs. revision & 0.1395 & 0.0667 & 0.0543 & 0.2381 \\
Max. abs. revision & 0.6249 & 0.3681 & 0.2534 & 0.9627 \\
\hline
\end{tabular}

Note: Standard deviation of revisions in parentheses.

find revisions affecting GDP to be lowest in the E.A., somewhat higher in the U.S. and highest in Japan.

Moreover, we find that the dynamics of revisions are different across countries. Figure 3 shows GDP releases for $2003 q 4$ for every country. Whereas $\Delta g d p_{t}$ got revised continuously in Switzerland, the E.A. and Japan, this is not true for the U.S. There, revisions take place less frequently, but are generally larger when they occur. For example, looking at the upper left panel (Switzerland) and the upper right panel (U.S.), it appears that both mean revisions and mean absolute revisions are higher in Switzerland. However, the range of releases $\left(\max \left(\Delta g d p_{t}^{v}\right)-\min \left(\Delta g d p_{t}^{v}\right)\right)$ is approximately the same in both countries and, hence, looking at first versus last revisions in Table 3 results in similar mean revisions and mean absolute revisions.

This small exercise shows that if one is to evaluate revisions and compare them internationally, it may be important to bear in mind how the figures are computed by the statistical agencies and what particular revision policy they adhere. Revision statistics and hence statistical tests can be influenced by particular features of the data generating processes. 
Figure 3: Revision History, 2003q4, Cross-Country Comparison

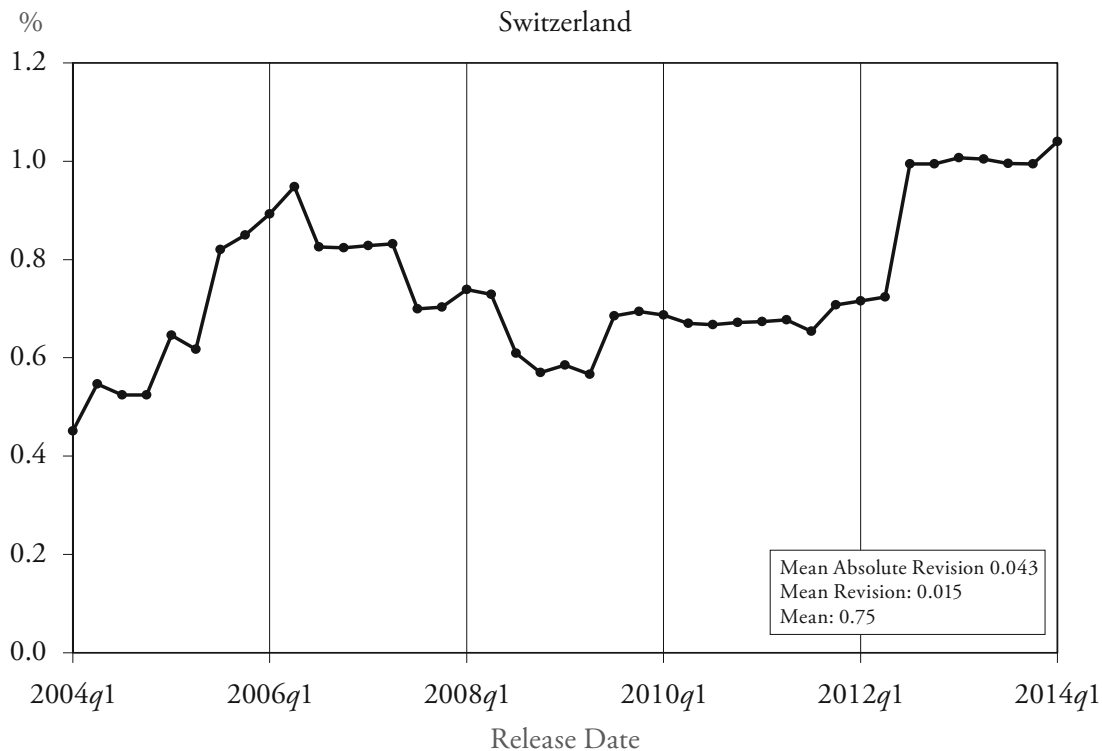

$\% \quad$ USA

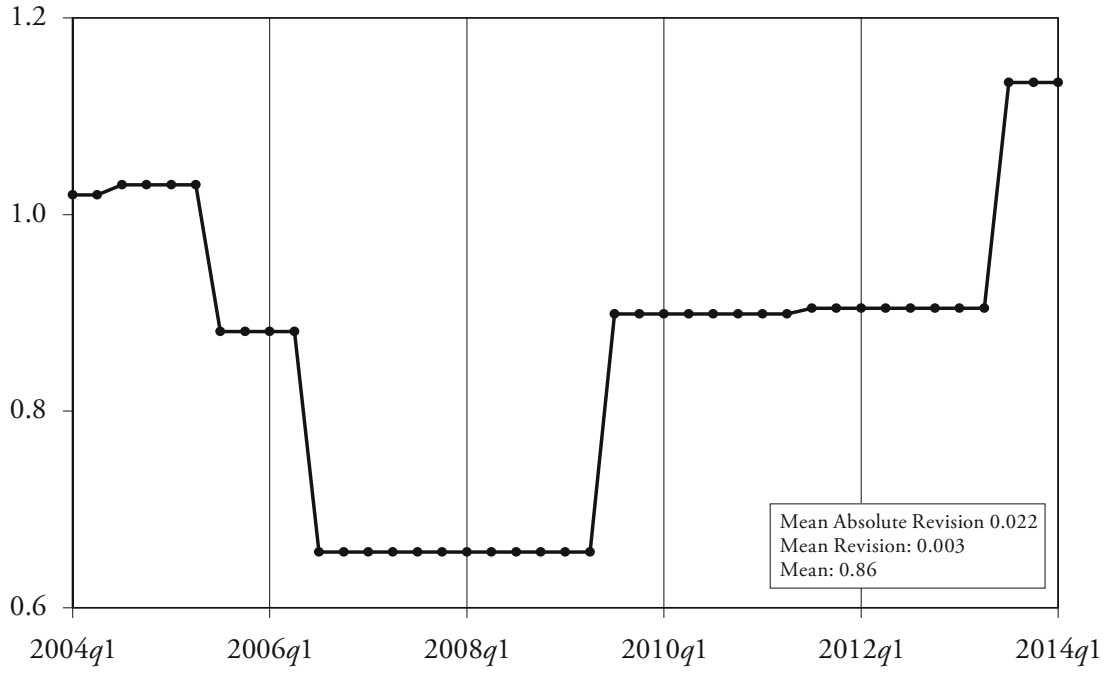

Release Date 

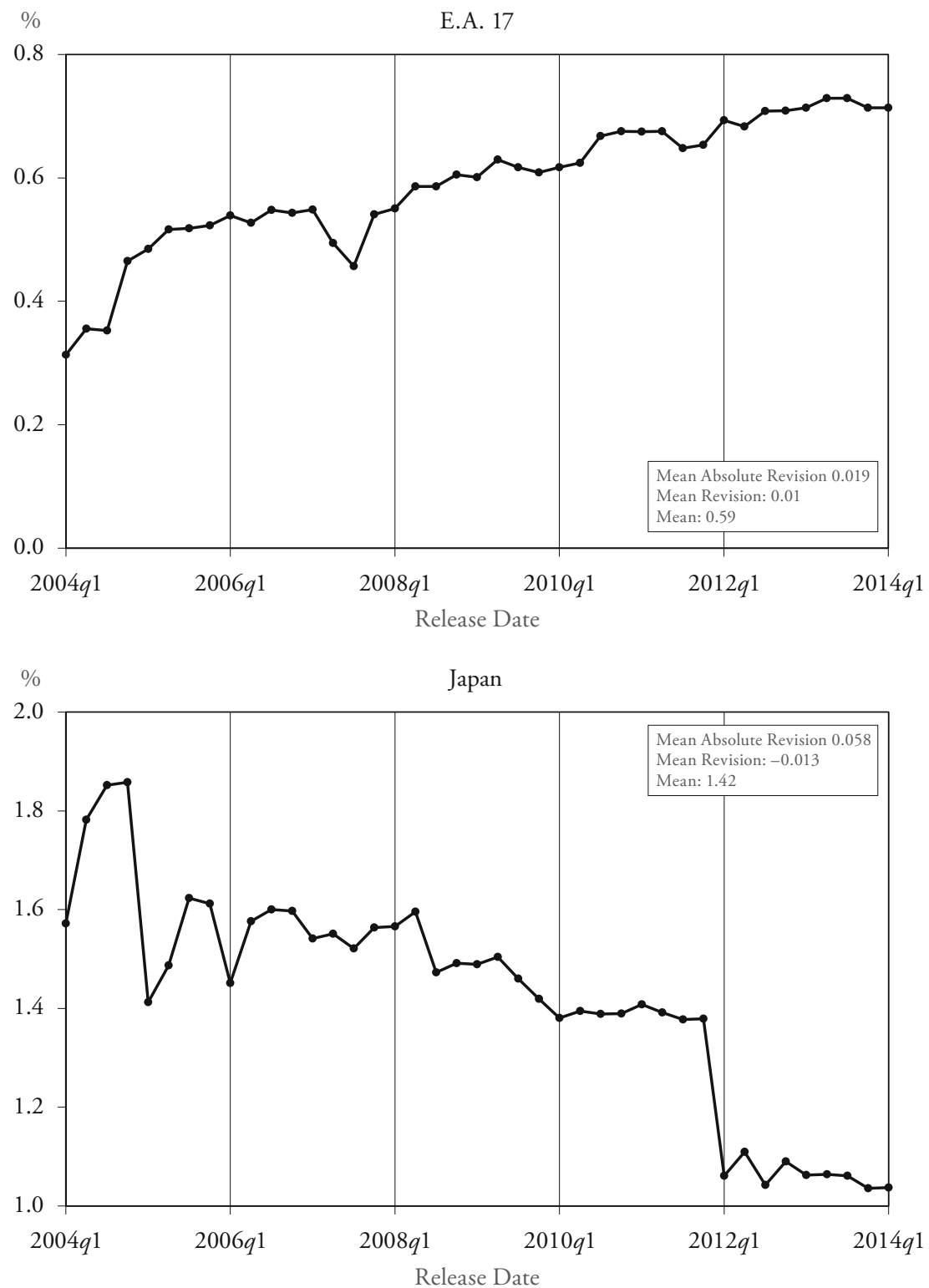

Notes: All panels show the country's GDP growth rate of the fourth quarter 2003 as released in different vintages. Note that the scale of the vertical axis changes. The statistics depicted in the upper right of each panel only involve data for $2003 q 4$. I.e., revisions are calculated as $r e v_{2003 q 4}^{v}=\Delta g d p_{2003 q 4}^{v+1}-\Delta g d p_{2003 q 4}^{v}$. 


\section{Conclusion}

The accuracy of initial estimates of economic variables and the importance of data revisions can only be evaluated by using appropriate and comprehensive realtime data sets as indicated by Eurostat (2013). Moreover, the literature strongly advises the use of real-time data for economic forecasting and policy evaluation if large data revisions occur. Furthermore, it has been shown that it is advisable to check the robustness of empirical economic results across different data vintages if data revisions are present and large. This paper describes such a data set for Switzerland. It contains many important economic variables with quarterly frequency that are subject to revisions. The exercise in the second part of this paper indicates that the magnitude of revisions to quarterly national accounts data of Switzerland are comparable to those of other countries. However, one should be aware of particularities of the revision policies in different countries and their impact on the statistical analysis. Finally, the absence of any revisions would not necessarily be a sign of quality as the inclusion of newly available or revised data increases the precision of the quarterly estimates. 


\section{Appendix}

\section{Appendix A: Data Overview}

Table 4: Variables Contained in the Data Set

\begin{tabular}{|c|c|c|c|}
\hline Variable & Specification & Sources & Retropolated / Forecasted Vintages \\
\hline GDP & real, sa & OECD, SECO & $G D P_{1980 q 1-1989 q 4}^{2004 q 1}, G D P_{1980 q 1-1980 q 4}^{2006 q 2-2008 q 1}$ \\
\hline $\begin{array}{l}\text { Government } \\
\text { Consumption }\end{array}$ & real, sa & OECD, SECO & $G C_{1980 q 1-1989 q 4}^{2004 q 1}, G C_{1980 q 1-1980 q 4}^{2006 q 2-2008 q 1}$ \\
\hline $\begin{array}{l}\text { Private } \\
\text { Consumption }\end{array}$ & real, sa & OECD, SECO & $P C_{1980 q 1-1989 q 4}^{2004 q 1}, P C_{1980 q 1-1980 q 4}^{2006 q 2-2008 q 1}$ \\
\hline Gross Investment & real, sa & OECD, SECO & $I N V_{1980 q 1-1989 q 4}^{2004 q 1}, I N V_{1980 q 1-1980 q 4}^{2006 q 2-2008 q 1}$ \\
\hline Total Exports & real, sa & OECD, SECO & $E X P_{1980 q 1-1989 q 4}^{2004 q 1}, E X P_{1980 q 1-1980 q^{4}}^{2006 q 2-2008 q 1}$ \\
\hline Total Imports & real, sa & OECD, SECO & $I M P_{1980 q 1-1989 q 4}^{2004 q 1}, I M P_{1980 q 1-1980 q 4}^{2006 q 2-2008 q 1}$ \\
\hline GDP Deflator & sa & OECD, SECO & $D E F L_{1980 q 1-1989 q 4}^{2004 q 1}, D E F L_{1980 q 1-1900 q^{4}}^{2006 q 2-2008 q 1}$ \\
\hline $\begin{array}{l}\text { Consumer Price } \\
\text { Index }\end{array}$ & $\begin{array}{l}\text { nsa } \\
\text { sa }\end{array}$ & OECD, SFSO & $C P I_{1980 q 1-1982 q 4}^{2013 q 4-2014 q 2}$ \\
\hline $\begin{array}{l}\text { Nominal Interest } \\
\text { Rate }\end{array}$ & & SNB & $I_{1980 q 1-1988 q 4}^{2002 q 4-2014 q 2}$ \\
\hline \multicolumn{4}{|l|}{ Real Interest Rate } \\
\hline Employment (fte) & $\begin{array}{l}\text { nsa } \\
\text { sa }\end{array}$ & SECO, SFSO & $E M P L_{2011 q 1}^{2011 q 2}, E M P L_{2011 q 1-2011 q 2}^{2011 q 3}$ \\
\hline $\begin{array}{l}\text { Unemployment } \\
\text { Rate }\end{array}$ & $\begin{array}{l}\text { nsa } \\
\text { sa }\end{array}$ & SECO, SFSO & \\
\hline $\begin{array}{l}\text { Registered } \\
\text { Unemployed }\end{array}$ & $\begin{array}{l}\text { nsa } \\
\text { sa }\end{array}$ & SECO & \\
\hline GDP, USA & real, sa & FRED, OECD & \\
\hline GDP, E.A. 17 & real, sa & Eurostat, OECD & $\begin{array}{l}G D P . E A_{1980 q 1-1994 q 4}^{2007 q 2-2014 q 2} \\
G D P . E A_{2008 q 2}^{2008 q 3}, G D P . E A_{2008 q 2-2008 q 3}^{2008 q 4}\end{array}$ \\
\hline GDP, Japan & real, sa & $\begin{array}{l}\text { Cabinet Office }{ }^{21} \text {, } \\
\text { OECD }\end{array}$ & $G D P . J P_{1980 q 1-1993 q 4}^{2005 q 1-2009 q 2}, G D P . J P_{1980 q 1-1993 q 4}^{2012 q 1-2014 q 2}$ \\
\hline Foreign GDP & real, sa & & \\
\hline
\end{tabular}

21 http://www.esri.cao.go.jp/index-e.html. 
Appendix B: Construction of the Unemployment Rate

Deviating from the official calculation in order to mitigate the upward bias, the unemployment rate was calculated as

$$
U R_{t}^{v}=\frac{\text { Registered Unemployed }_{t}}{\text { Working Population }_{t}^{v}}
$$

where the working population, $W P_{t}^{v}$, is calculated as

$$
\frac{W P_{t}^{v<2003 q 1}}{\equiv W P^{1}}= \begin{cases}W P_{1980}+\left(\frac{W P_{1990}-W P_{1980}}{40}\right)\left(t-T_{0}\right), & \text { if } T_{0} \equiv 1980 q 1 \leq t<1990 q 1 \\ W P_{1980}, & \text { if } t \geq 1990 q 1\end{cases}
$$

$\frac{W P_{t}^{2003 q 1 \leq v<2012 q 4}}{\equiv W P^{2}}= \begin{cases}W P_{t}^{1}, & \text { if } t<1990 q 1 \equiv T_{1} \\ W P_{1990}+\left(\frac{W P_{2000}-W P_{1990}}{40}\right)\left(t-T_{1}\right), & \text { if } 1990 q 1 \leq t<2000 q 1 \\ W P_{2000}, & \text { if } t \geq 2000 q 1\end{cases}$

$W P_{t}^{2012 q 4 \leq v}= \begin{cases}W P_{t}^{2}, & \text { if } t<2000 q 1 \equiv T_{2} \\ W P_{2000}+\left(\frac{W P_{2010}-W P_{2000}}{40}\right)\left(t-T_{2}\right), & \text { if } 2000 q 1 \leq t<2010 \\ W P_{2010}, & \text { if } t \geq 2010\end{cases}$

Appendix C: Construction of the Proxy for Foreign GDP

$$
\begin{aligned}
N G D P_{t}^{f, v}= & N G D P_{t}^{e a, v}+N G D P_{t}^{u s, v}+N G D P_{t}^{j p, v} \\
\Delta g d p_{t}^{f, v}= & \frac{N G D P_{t}^{e a, v-1}}{N G D P_{t}^{f, v-1}} \Delta g d p_{t}^{e a, v}+\frac{N G D P_{t}^{u s, v-1}}{N G D P_{t}^{f, v-1}} \Delta g d p_{t}^{u s, v} \\
& +\frac{N G D P_{t}^{j p, v-1}}{N G D P_{t}^{f, v-1}} \Delta g d p_{t}^{j p, v} \forall t<T \\
\Delta g d p_{t}^{f, v}= & \frac{N G D P_{t-1}^{e a, v-1}}{N G D P_{t-1}^{f, v-1}} \Delta g d p_{t}^{e a, v}+\frac{N G D P_{t-1}^{u s, v-1}}{N G D P_{t-1}^{f, v-1}} \Delta g d p_{t}^{u s, v} \\
& +\frac{N G D P_{t-1}^{j p, v-1}}{N G D P_{t-1}^{f, v-1}} \Delta g d p_{t}^{j p, v} \text { for } t=T
\end{aligned}
$$




\section{Appendix D: Seasonal Adjustment}

Most series get seasonally adjusted by the data producing agencies. Whenever this was not the case, we used the R-interface by SAX (2014) which provides an easy accesses to the new X-13ARIMA-SEATS seasonal adjustment method described in U.S. Census Bureau (2013). We use the automated procedure without outliers. Table 5 provides details about the models which got applied by the automated procedure. One may raise the objection that X-13ARIMA-SEATS is a very new technology and could not be accessed in real-time. While this is true, it remains impossible to guess what exact seasonal adjustment method might have been applied at a particular point in time in the past. However, the automated procedure for model selection keeps the real-time aspect of seasonal adjustment to a certain extend. Furthermore, the not seasonally adjusted series are also made available in the data set.

Table 5: Seasonal Adjustment Methods

\begin{tabular}{lll}
\hline Variable & Vintage & SARIMA-Model \\
\hline Consumer Price Index & $2002 q 4$ & $(1,1,0)(1,0,0)$ \\
& $2003 q 1-2003 q 2$ & $(1,1,1)(1,0,0)$ \\
& $2003 q 3-2006 q 3$ & $(1,1,0)(1,0,0)$ \\
& $2006 q 4$ & $(2,1,0)(1,0,0)$ \\
& $2007 q 1-2007 q 3$ & $(1,1,0)(1,0,0)$ \\
& $2007 q 4-2014 q 2$ & $(1,1,0)(0,1,1)$ \\
\hline Employment (fte) & $2002 q 4-2009 q 1$ & $(0,1,0)(0,1,1)$ \\
& $2009 q 2-2012 q 3$ & $(0,1,2)(1,0,0)$ \\
& $2012 q 4-2014 q 2$ & $(0,1,2)(0,1,0)$ \\
\hline Unemployment Rate & $2002 q 4-2003 q 4$ & $(1,1,0)(1,0,0)$ \\
& $2004 q 1-2009 q 4$ & $(1,1,1)(1,0,0)$ \\
& $2010 q 1$ & $(2,1,0)(1,0,0)$ \\
& $2010 q 2$ & $(2,1,2)(1,0,0)$ \\
& $2010 q 3-2010 q 4$ & $(2,1,1)(0,1,0)$ \\
& $2011 q 1-2011 q 2$ & $(2,0,0)(0,1,0)$ \\
& $2011 q 3$ & $(2,1,1)(1,0,0)$ \\
& $2011 q 4-2014 q 2$ & $(2,0,0)(0,1,0)$ \\
\hline \multirow{2}{*}{ Registered Unemployed } & $2002 q 4-2003 q 4$ & $(1,1,0)(1,0,0)$ \\
& $2004 q 1-2009 q 4$ & $(1,1,0)(1,0,0)$ \\
& $2010 q 1$ & $(2,1,0)(1,0,0)$ \\
& $2010 q 2$ & $(2,0,1)(0,1,0)$ \\
& $2010 q 3-2011 q 4$ & $(2,1,1)(0,1,0)$ \\
& $2012 q 1-2013 q 1$ & $(2,0,0)(0,1,0)$ \\
& $2011 q 4-2014 q 2$ & $(2,1,1)(0,1,0)$ \\
\hline
\end{tabular}




\section{References}

Amstad, Marlene, and Andreas M. Fischer (2009), "Are Weekly Inflation Forecasts Informative?", Oxford Bulletin of Economics and Statistics, 71(2), pp. 137-252.

Anderson, Richard G. (2006), "Replicability, Real-Time Data, and the Science of Economic Research: FRED, ALFRED, and VDC”, Federal Reserve Bank of St. Louis Review, 88(1), pp. 11-93.

Aruoba, S. BoraĞan (2008), "Data Revisions Are Not Well Behaved", Journal of Money, Credit and Banking, 40(2-3), pp. 119-340.

Bernhard, Severin (forthcoming), "A Real-time GDP Data Set for Switzerland", Swiss National Bank, Economic Studies.

Castle, Jennifer L., and Colin Ellis (2002), "Building a Real-Time Database for GDP (E)”, Bank of England Quarterly Bulletin, 42(1), pp. 12-49.

Corradi, Valentina, Andres Fernandez, and Norman R. Swanson (2009), "Information in the Revision Process of Real-Time Datasets", Journal of Business \& Economic Statistics, 27(4), pp. 155-467.

Croushore, Dean (2011), "Frontiers of Real-Time Data Analysis", Journal of Economic Literature, 49(1), pp. 12-100.

Croushore, Dean, and Charles L. Evans (2006), "Data Revisions and the Identification Of Monetary Policy Shocks", Journal of Monetary Economics, 53(6), pp. 1135-1160.

Croushore, Dean, and Tom Stark (2001), "A Real-Time Data Set for Macroeconomists”, Journal of Econometrics, 105(1), pp. 111-130.

Croushore, Dean, and Tom Stark (2003), "A Real-Time Data Set for Macroeconomists: Does the Data Vintage Matter?", Review of Economics and Statistics, 85(3), pp. 105-617.

Cuche-Curti, Nicolas, Pamela Hall, and Attilio Zanetti (2008), "Swiss GDP Revisions: A Monetary Policy Perspective”, Journal of Business Cycle Measurement and Analysis, 2, pp. 183-213.

Cunningham, Alastair, Jana Eklund, Chris Jefferr, George Kapetanios, and Vincent Labhard (2012), "A State Space Approach to Extracting the Signal From Uncertain Data”, Journal of Business \& Economic Statistics, 30(2), pp. 173-180.

Diebold, Francis X. and Glenn D. Rudebusch (1991), "Forecasting Output With the Composite Leading Index: A Real-Time Analysis", Journal of the American Statistical Association, 86(415), pp. 103-610.

Egginton, Don M., Andreas Pick, and Shaun P. Vahey (2002), "Keep It Real!: A Real-Time UK Macro Data Set”, Economics Letters, 77(1), pp. 15-20. 
Eurostat (2008a), "Eurostatistics. Data for Short-Term Economic Analysis", (6). Eurostat (2008b), "Eurostatistics. Data for Short-Term Economic Analysis", (8). Eurostat (2013), Handbook on Quarterly National Accounts, Eurostat.

Faust, Jon, John H. Rogers, and Jonathan H. Wright (2005), "News and Noise in G-7 GDP Announcements", Journal of Money, Credit and Banking, 37(3), pp. 103-419.

Fernandez, Adriana Z., Houston Branch, Evan F. Koenig, and Alex Nikolsko-Rzhevskyy (2012), "A Real-Time Historical Database for the OECD”, Federal Reserve Bank of Dallas, Globalization and Monetary Policy Institute Working Paper, (96).

Giannone, Domenico, Jérôme Henry, Magdalena lalik, and Michele Modugno (2012), "An Area-Wide Real-Time Database for the Euro Area", Review of Economics and Statistics, 94(4), pp. 1000-1013.

Jacobs, Jan P.A.M., and Jan-Egbert Sturm (2008), "The Information Content of KOF Indicators on Swiss Current Account Data Revisions", Journal of Business Cycle Measurement and Analysis, 4(2), pp. 163-183.

Jacobs, Jan P.A.M., and Simon Van Norden (2011), "Modeling Data Revisions: Measurement Error and Dynamics of 'True' Values", Journal of Econometrics, 161(2), pp. 101-109.

Jordan, Thomas J., Peter Kugler, Carlos Lenz, and Marcel R. Savioz (2005), "GDP Data Revisions and Forward-Looking Monetary Policy in Switzerland", The North American Journal of Economics and Finance, 16(3), pp. 151-372.

Kholodilin, Konstantin A., and Boriss Siliverstovs (2012), "Assessing the Real-Time Informational Content of Macroeconomic Data Releases for Now-/Forecasting GDP: Evidence for Switzerland”, Jahrbücher für Nationalökonomie und Statistik, 232(4), pp. 129-444.

Knetsch, Thomas A. (2009), "The German Real-Time Database Gerda: Content, Structure, Search and Download", Tech. rep., Deutsche Bundesbank.

Orphanides, Athanasios (2001), "Monetary Policy Rules Based on Real-Time Data", American Economic Review, pp. 164-985.

Orphanides, Athanasios, and Simon Van Norden (2005), "The Reliability of Inflation Forecasts Based on Output Gap Estimates in Real Time", Journal of Money, Credit, and Banking, 37(3), pp. 183-601.

Sax, Christoph (2014), Seasonal: R interface to X-13ARIMA-SEATS, URL http://CRAN.R-project.org/package=seasonal, R package version 0.60.0.

Sax, Christoph, and Peter Steiner (2013), "Temporal Disaggregation of Time Series", R Journal, 5(2). 
SECO (2014), „Die Lage auf dem Arbeitsmarkt, April 2014“, Tech. rep., State Secretariat for Economic Affairs.

Siliverstovs, Boriss (2012), "Are GDP Revisions Predictable? Evidence for Switzerland", Applied Economics Quarterly, 58(4), pp. 199-326.

Siliverstovs, Boriss (2013), "Dating Business Cycles in Historical Perspective: Evidence for Switzerland”, Jahrbücher für Nationalökonomie \& Statistik, 233(5), pp. 161-679.

U.S. Census Bureau (2013), "X-13Arima-SEATS Reference Manual”, Tech. rep., U.S. Census Bureau, Statistical Research Division.

\section{SUMMARY}

Accessibility of real-time data is crucial for applied macroeconomic researchers who aim at evaluating forecasts, policy decisions or the accuracy of initial data estimates. To the extent of our knowledge, no appropriate and comprehensive real-time data set has been published for Switzerland so far. This paper introduces such a data set, which can be downloaded online. The balanced database includes quarterly, seasonally adjusted vintages of the most important economic variables on the national level. A short analysis of data revisions is provided for quarterly GDP. The magnitude of revisions are comparable to other countries such as the Euro Area or the United States. However, revision policy may differ considerably and potentially influence a statistical analysis. 